\title{
What does being on a community treatment orders entail? A 3-year follow-up of the OCTET CTO cohort
}

\author{
Jorun Rugkåsa ${ }^{1,2}$ (1) Ksenija Yeeles $^{2} \cdot$ Constantinos Koshiaris $^{3} \cdot$ Tom Burns $^{2}$
}

Received: 25 August 2016/Accepted: 24 October 2016/Published online: 5 November 2016

(C) Springer-Verlag Berlin Heidelberg 2016

\begin{abstract}
Purpose Community Treatment Orders lack evidence of effectiveness. Very little is known about how they are used in practice and over time in terms of what it obliges patients to do and the judicial threshold for remaining on an order.

Aims To investigate CTO implementation in England in terms of the use of specified conditions, and judicial hearings; whether these change over time, and; the level of continued coercion.

Method 36-month observational prospective study of patients on CTO in the OCTET follow-up study.

Results The number of CTO conditions remained stable over time but consolidated around medication adherence and remaining in contact with services. Ten percent of Mental Health Tribunal Hearings and only 1 percent of Hospital Managers Hearings resulted in discharge. Twenty-seven percent of patients experienced more than one CTO episode and eighteen percent remained under compulsion until the end of follow-up.

Conclusions CTOs seem to be used primarily to oblige patients to take medication and stay in contact with services. There is agreement between clinical and legal judgements about their appropriateness and threshold for
\end{abstract}

Jorun Rugkåsa, Ksenija Yeeles are joint first authors.

Jorun Rugkåsa

jorun.rugkasa@ahus.no

$1 \quad$ Health Services Research Unit, Akershus University Hospital, 1478 Lørenskog, Norway

2 Department of Psychiatry, University of Oxford, Oxford, UK

3 Department of Primary Care, University of Oxford, Oxford, UK use. A pattern of continuous coercion for a significant group of patients raises concerns. If CTOs are to be continued to be imposed, their use should be carefully monitored with further cohort studies with long-term follow-up.

Keywords Coercion - Community Treatment Orders . Outpatient commitment $\cdot$ Psychosis

\section{Introduction}

As mental health services increasingly are delivered in the community, Community Treatment Orders (CTOs), legal regimes for involuntary treatment when the patient lives at home, have been introduced and are now available in more than 75 jurisdictions worldwide [1]. CTOs make it a legal requirement for patients to adhere to a treatment regime. Their introduction often causes prolonged debates. Some welcome them as a potentially less restrictive alternative to involuntary hospitalisation, while others fear, they will extend compulsion and represent a legal 'lobster pot' for patients: easy to enter, but difficult to exit [2]. Across jurisdictions CTOs are broadly similar in their operation, despite differences in legal frameworks.

CTOs became available in England and Wales when the amended Mental Health Act (MHA) took effect in November 2008 [3]. The legal criteria include that the patient suffers from a mental disorder for which they require treatment to protect their health and safety or that of others, that the treatment can continue in the community, and that the patient is liable to be recalled to hospital. In England and Wales, a CTO can only be made when the patient is detained for involuntary treatment (under Section 3 or 37 of the MHA). In many other jurisdictions, CTOs can be imposed in the community, although in 
practice, they are almost always introduced in connection with discharge from hospital [4].

All CTOs in England and Wales have two mandatory conditions. These require the patient to make themselves available for assessments (1) when an independent medical practitioner is assessing the appropriateness of treatment and (2) when renewal of the CTO is considered. In addition, discretionary conditions may be specified in the CTO form, based on the knowledge of the individual patient. Local small studies or audits report that the most frequently used conditions are to take mediation and to engage with the treatment team [5-7]. Should the patient breach a mandatory condition or deteriorate, he or she may be recalled to hospital for up to $72 \mathrm{~h}$, after which they either remain in hospital for involuntary treatment (revocation of the order), continue on a CTO in the community, or are discharged from compulsion altogether. The CTO lasts initially for 6 months, is renewable for a further six months and then for subsequent 12-month periods. The orders can be ended by the psychiatrist at any time. The patient has the right to appeal to managers of the treating hospital and to one hearing by the Mental Health Review Tribunal (MHRN) in each CTO period. Routine hearings are held even if the patient does not appeal to ensure that the legal criteria are still met. The prevalence of CTO has increased with about $10 \%$ year on year [8]. On 31 March 2015, 5461 people were on an order. In the year 2014/15, of 3550 CTO hearings by the Mental Health Review Tribunals (MHRT), $185(5.2 \%)$ ended with the patient being discharged from the CTO. A tribunal discharge rate of around $5 \%$ has remained steady since 2008 [8].

The international research evidence shows no effect of CTOs on their stated purpose of reducing relapse and readmission [9-12] or on a wide range on social and clinical outcomes $[12,13]$. This was confirmed by the Oxford Community Treatment Evaluation Trial (OCTET) that tested the English regime [14, 15] which additionally found no effect on long-term (36 months) hospital outcomes or on disengagement from services [16]. We detected no effect on subgroups of patients [15] but found that, contrary to concern, the recall mechanism was used in the same way as in the mature system now 8 years after introduction [17].

The lack of observed positive effects of CTOs has surprised many. It has been suggested that CTO regimes need time to bed in before they are used optimally, so that patients benefit $[18,19]$. Little is known, however, about how CTOs work in practice. In particular, we need to ascertain: (1) the content of the orders: what is it that patients are ordered to do? and (2) the boundaries around CTOs: whether the legal and clinical threshold for remaining on an order once on it correspond. We report a longitudinal, descriptive analysis of 3-year follow-up data on patients on CTO in the OCTET follow-up study [16]. Specifically, we examine the content of CTO conditions and the outcomes of hearings by the MHRT and Hospital Managers including whether they change over time. We also establish the level of continued coercion for patients with more than one CTO episode.

\section{Methods}

\section{Sample and procedures}

The OCTET trial randomised patients from 32 NHS hospitals across England. All were in involuntary hospital treatment, aged 18-65 years, diagnosed with psychosis, and considered to need CTO on discharge. Patients were randomised to leave hospital on a CTO or to voluntary status via brief Section 17 leave of absence and followedup for 12 months [14]. The OCTET follow-up study then followed the cohort of 333 patients for further 24 months (i.e., 36 months, 1095 days, in total) [16]. For the present observational prospective cohort study, we selected those patients from the OCTET follow-up study who at any time during the 36 months were on a CTO. No further inclusion or exclusion criteria were applied.

For each patient, we used data from the date of first placement on a CTO until 36 months after randomisation in the original trial. Independent researchers collected data from NHS medical records, including trusts' Mental Health Act Offices. Socio-demographic and clinical characteristics were collected through patient interviews at baseline $[14,16]$. Data collection ran between November 2008 and February 2014.

\section{Variables}

For discretionary CTO conditions, we collected the type and number of conditions specified on each CTO form. As conditions are written into the form by hand, wording can vary; after the data were collected, we classified them into the 16 categories reported.

For hearings by hospital managers and the Mental Health Review Tribunal (MHRT), we counted the number of occurrences and classified the outcomes in three predefined categories (continued CTO; discharge to voluntary care; adjournment). Only hearings related to CTOs were included.

To allow investigation of whether practice changed over time, either with experience of individual patients or with increased familiarity with the CTO regime, we used two separate methods. First, to test increasing familiarity with individual patients, we examined the conditions imposed in patients' successive CTO episodes (1-4) and the reason for 
and outcome of their first, second, third, and fourth hearings. Second, to test increasing familiarity with the CTO regime over time, we divided the data on patients' first CTOs or hearings in two time periods: period 1 , the 0-12 months of a patient's participation in the study (0-365 days) and period 2, 13-36 months in the study (366-1095 days). Most CTOs were initiated in period 1 by randomisation in the original trial. To enable a meaningful comparison with the smaller sample of later CTOs, period 2 is not divided by years.

We defined a CTO episode to include renewals where applicable. If a CTO was revoked or discharged and the patient subsequently again placed on a CTO, we considered this a new CTO episode. This meant that a patient could be under continuous coercive treatment between two CTO episodes (e.g., as an involuntary inpatient), or they could have a period as a voluntary patient in between. For those with more than one CTO episode, we noted legal status between episodes to identify continuous coercion.

Global functioning and severity of symptoms were assessed at baseline, using the Global Assessment of Functioning (GAF) [20] and the Brief Psychiatric Rating Scale (BPRS) [21], respectively.

\section{Statistical analysis}

We report the number and percentage of observed values for binary and categorical variables and, depending on data distribution, mean with standard deviation (SD) or median with interquartile range (IQR) for continuous variables. The descriptive statistics are provided for the whole sample and by time period.

\section{Ethical considerations}

Ethical approval was granted by the Staffordshire National Health Service (NHS) Research Ethics Committee (ref: 08/H1204/131). We obtained patients' informed consent in writing prior to enrolment. OCTET is a registered trial (registration number ISRCTN73110773).

\section{Results}

\section{Sample and baseline characteristics}

One hundred and ninety eight of the three hundred and thirty three patients in the OCTET follow-up study were subject to a CTO during the 36 months, and were included in this analysis. Table 1 outlines their socio-demographic and clinical characteristics.
Two-thirds of patients were male $(68 \%, 135 / 198)$ and the mean age was 39.6 (SD 11.2). Mean of years of education was 11.9 (SD 1.7, 12 years of education is mandatory in the UK). In terms of ethnicity, more than half were White $(58 \%, 114 / 198)$, a quarter Black $(26 \%, 51 / 198)$ and the remainder of Asian (10\%19/198), or mixed and 'other' ethnic origin $(7 \%, 14 / 198)$. The majority of patients were diagnosed with schizophrenia $(84 \%, 166 / 198)$. The median duration of illness was 12 years (IQR 6, 20), the median level of symptoms, measured by the BPRS, was 39 (IQR $33,45)$, and the median level of functioning as measured by the GAF was 38.5 (IQR 31, 48.5). They had a median of six (IQR 3,9) previous hospital admissions, with median duration of 16 months (IQR 8, 28). This indicates a group of people with major impairments and long histories of illness. Nearly half the sample $(42 \%)$ had criminal convictions and almost one in three (28\%) had been imprisoned.

\section{CTO conditions}

The 198 patients experienced a total of 268 CTOs. The conditions specified on the CTO forms are presented in Table 2 which also shows which conditions applied to patients' first, second, third, and fourth CTOs, and the conditions that applied to first CTOs episodes in periods 1 and 2. Data were missing for one patient; the analysis of conditions, therefore, includes 197 patients.

The 268 CTOs had 768 recorded conditions. By far, the most common was to comply with medication, which was imposed in $96 \%$ of CTOs (259/268). By the patients' third and fourth CTOs, this condition was imposed in all, and it was imposed for all first CTO episodes in period 2.

The second most frequent condition was to attend appointments with the mental health team (specified in $80 \%$ of CTOs, 214/268). There was a decrease from $83 \%$ $(141 / 170)$ for patients who were first put on a CTO in period 1 to 63\% (17/27) for those who had their first CTO in period 2. Other conditions were also related to keeping in contact with the team. These are classified under 'General engagement with team' and include conditions like 'accept help from the team' and 'work with the support workers'. 'Allowing access' contains various specified requirements for allowing clinicians to see patients, and was included in 19\% (51/268) of CTOs, increasing from $15 \%(26 / 170)$ to $26 \%(7 / 27)$ from period 1 to period 2.

The third most frequent condition was compliance with residency requirements, which was used in 29\% (77/ 268) of CTOs, and this was a constant proportion across successive CTOs and time periods, except that it was higher (43\%) among the small number of patients on their third CTO (6/14). 
Table 1 Patients' characteristics at baseline $(n=198)$

\begin{tabular}{|c|c|c|c|c|}
\hline & \multicolumn{2}{|c|}{ Missing data } & \multirow{2}{*}{\multicolumn{2}{|c|}{$\begin{array}{l}n / \%, \text { mean }(\mathrm{SD}) \\
\text { median }[\mathrm{IQR}]\end{array}$}} \\
\hline & $n$ & $\%$ & & \\
\hline \multicolumn{5}{|l|}{ Demographics } \\
\hline Age (years) & 0 & 0 & 39.6 & $(11.2)$ \\
\hline Male & 0 & 0 & 135 & $68 \%$ \\
\hline Years of education & 3 & 2 & 11.9 & (1.7) \\
\hline Ethnicity & 0 & 0 & - & - \\
\hline White & - & - & 114 & $58 \%$ \\
\hline Black & - & - & 51 & $26 \%$ \\
\hline Asian & - & - & 19 & $10 \%$ \\
\hline Mixed and other & - & - & 14 & $7 \%$ \\
\hline Born in UK & 0 & 0 & 155 & $78 \%$ \\
\hline \multicolumn{5}{|l|}{ Social/living situation } \\
\hline Married/co-habiting & 1 & 1 & 16 & $8 \%$ \\
\hline Patients with identified family carer & 20 & 10 & 72 & $36 \%$ \\
\hline Independent accommodation & 2 & 1 & 147 & $74 \%$ \\
\hline Living alone/homeless & 12 & 6 & 143 & $72 \%$ \\
\hline \multicolumn{5}{|l|}{ Clinical status } \\
\hline Schizophrenia & 0 & 0 & 166 & $84 \%$ \\
\hline Brief Psychiatric Rating Scale (BPRS) & 14 & 7 & 39 & {$[33,45]$} \\
\hline Global Assessment of Functioning (GAF) & 15 & 8 & 38.5 & {$[31,48.5]$} \\
\hline \multicolumn{5}{|l|}{ Clinical history } \\
\hline Duration of illness (years) $^{\mathrm{a}}$ & 4 & 2 & 12 & {$[6,20]$} \\
\hline Duration of illness less than 2 years ${ }^{b}$ & 0 & 0 & 7 & $4 \%$ \\
\hline Number of past hospital admissions & 11 & 6 & 6 & {$[3,9]$} \\
\hline Months of past hospitalisation & 29 & 15 & 16 & {$[8,28]$} \\
\hline $\begin{array}{l}\text { Number of past involuntary hospital } \\
\text { admissions }\end{array}$ & 19 & 10 & 4 & {$[2,7]$} \\
\hline \multicolumn{5}{|l|}{ Criminal history } \\
\hline Criminal convictions & 15 & 8 & 83 & $42 \%$ \\
\hline Imprisonment & 13 & 7 & 55 & $28 \%$ \\
\hline
\end{tabular}

CTO community treatment orders, $I Q R$ interquartile range, $S D$ standard deviation, - not applicable

${ }^{a}$ Patient reported

${ }^{\mathrm{b}}$ Clinician reported

Blood testing to screen for adherence to oral medication was used as a condition in $10 \%$ of cases (27/268). A range of other conditions, used in less than $10 \%$ of CTOs, included attending psychological treatment, allowing family involvement, attending their General Practitioner for physical checks, engaging with social rehabilitation, and permitting residential staff to supervise medication consumption. The use of these conditions was relatively stable across periods 1 and 2 . The conditions classified as 'Other' included very specific requirements, such as 'stay out of trouble with the police', 'shower twice weekly', 'do not email Dr. X', or 'allow staff to support management of finances'. Such specific conditions were not used beyond patients' second CTO.

As patients moved onto their third or fourth CTO, the number of conditions remained constant at around three per
CTO. There was, however, less variety in the conditions in later CTOs than in earlier CTOs. Nine categories of conditions were not used in third and eleven were not used in fourth CTOs. The same tendency can be seen over time, with greater variety in period 1 than period 2 .

\section{Tribunals and manager hearings}

Table 3 shows that 76\% (105/139) of the recorded MHRT hearings ended with the patient remaining on a CTO. Ten percent (14/139) of hearings ended in discharge from involuntary treatment, and thirteen percent (18/139) were adjourned.

Ninety five percent (163/172) of the recorded hearings by managers resulted in continued CTO, one percent $(2 /$ $172)$ in discharge, and four percent $(7 / 163)$ were 
Table 2 CTO Conditions over 36 months by CTO and by time period

\begin{tabular}{|c|c|c|c|c|c|c|c|c|c|c|c|c|c|c|}
\hline & \multirow{2}{*}{\multicolumn{2}{|c|}{$\begin{array}{l}\text { All CTO } \\
\text { episodes } \\
\left(N=268^{\mathrm{a}}\right. \\
\text { CTOs })\end{array}$}} & \multirow{2}{*}{\multicolumn{2}{|c|}{$\begin{array}{l}\text { 1st CTO } \\
\text { episode } \\
(N=197)^{\mathrm{a}}\end{array}$}} & \multirow{2}{*}{\multicolumn{2}{|c|}{$\begin{array}{l}\text { 2nd CTO } \\
\text { episode } \\
(N=53)\end{array}$}} & \multirow{2}{*}{\multicolumn{2}{|c|}{$\begin{array}{l}\text { 3rd CTO } \\
\text { episode } \\
(N=14)\end{array}$}} & \multirow{2}{*}{\multicolumn{2}{|c|}{$\begin{array}{l}\text { 4th CTO } \\
\text { episode } \\
(N=4)\end{array}$}} & \multicolumn{4}{|c|}{ 1st CTO episode ${ }^{\mathrm{a}}$} \\
\hline & & & & & & & & & & & \multicolumn{2}{|c|}{$\begin{array}{l}0-12 \text { th } \\
\text { month } \\
(N=170)\end{array}$} & \multicolumn{2}{|c|}{$\begin{array}{l}13 \text { th-36th } \\
\text { month } \\
(N=27)\end{array}$} \\
\hline & $n$ & $\%$ & $n$ & $\%$ & $n$ & $\%$ & $n$ & $\%$ & $n$ & $\%$ & $n$ & $\%$ & $n$ & $\%$ \\
\hline Adhere to medication & 259 & 96 & 189 & 96 & 52 & 98 & 14 & 100 & 4 & 100 & 162 & 95 & 27 & 100 \\
\hline Attend appointments with mental health team & 214 & 80 & 158 & 80 & 43 & 81 & 9 & 64 & 4 & 100 & 141 & 83 & 17 & 63 \\
\hline Comply with residency requirements & 77 & 29 & 57 & 29 & 13 & 25 & 6 & 43 & 1 & 25 & 50 & 29 & 7 & 26 \\
\hline Allow access & 51 & 19 & 33 & 17 & 14 & 26 & 4 & 29 & 0 & 0 & 26 & 15 & 7 & 26 \\
\hline General engagement with team & 49 & 18 & 29 & 15 & 13 & 25 & 5 & 36 & 2 & 50 & 20 & 12 & 9 & 33 \\
\hline Blood/urine drug screen & 27 & 10 & 18 & 9 & 7 & 13 & 1 & 7 & 1 & 25 & 14 & 8 & 4 & 15 \\
\hline Blood test, adherence to oral medication & 17 & 6 & 15 & 8 & 1 & 2 & 1 & 7 & 0 & 0 & 12 & 7 & 3 & 11 \\
\hline Abstain from illegal drug use & 15 & 6 & 13 & 7 & 2 & 4 & 0 & 0 & 0 & 0 & 11 & 6 & 2 & 7 \\
\hline Comply with treatment plan (beyond medication) & 12 & 4 & 11 & 6 & 1 & 2 & 0 & 0 & 0 & 0 & 11 & 6 & 0 & 0 \\
\hline Attend drug/alcohol abuse treatment & 8 & 3 & 7 & 4 & 1 & 2 & 0 & 0 & 0 & 0 & 7 & 4 & 0 & 0 \\
\hline Attend psychological therapies & 8 & 3 & 6 & 3 & 2 & 4 & 0 & 0 & 0 & 0 & 6 & 4 & 0 & 0 \\
\hline Accepting family involvement & 6 & 2 & 5 & 3 & 1 & 2 & 0 & 0 & 0 & 0 & 4 & 2 & 1 & 4 \\
\hline Attend GP for physical health checks & 5 & 2 & 3 & 2 & 2 & 4 & 0 & 0 & 0 & 0 & 3 & 2 & 0 & 0 \\
\hline Engage with social rehabilitation & 4 & 1 & 3 & 2 & 1 & 2 & 0 & 0 & 0 & 0 & 2 & 1 & 1 & 4 \\
\hline $\begin{array}{l}\text { Permit residential staff to supervise taking of } \\
\text { medication }\end{array}$ & 4 & 1 & 3 & 2 & 1 & 2 & 0 & 0 & 0 & 0 & 2 & 1 & 1 & 4 \\
\hline Other & 12 & 4 & 9 & 5 & 3 & 6 & 0 & 0 & 0 & 0 & 7 & 4 & 2 & 7 \\
\hline
\end{tabular}

GP general practitioner

${ }^{\text {a }}$ One patient was excluded because of missing data on CTO conditions for the first CTO episode

Table 3 Outcomes of hearings by the Mental Health Review Tribunal and hospital managers over 36 months by CTO

\begin{tabular}{|c|c|c|c|c|c|c|c|c|c|c|}
\hline & \multicolumn{2}{|c|}{ All MHRT hearings $(N=139)$} & \multicolumn{2}{|c|}{ 1st $(N=77)$} & \multicolumn{2}{|c|}{ 2nd $(N=42)$} & \multicolumn{2}{|c|}{$3 \mathrm{rd}(N=14)$} & \multicolumn{2}{|c|}{4 th-6th $(N=6)$} \\
\hline & $n$ & $\%$ & $n$ & $\%$ & $n$ & $\%$ & $n$ & $\%$ & $n$ & $\%$ \\
\hline \multicolumn{11}{|l|}{ Tribunal outcomes } \\
\hline Continued CTO & 105 & 76 & 58 & 75 & 31 & 74 & 11 & 78 & 5 & 83 \\
\hline Discharged to voluntary care & 14 & 10 & 9 & 12 & 5 & 12 & 0 & 0 & 0 & 0 \\
\hline Adjournment & 18 & 13 & 10 & 13 & 5 & 12 & 2 & 1 & 1 & 17 \\
\hline \multirow[t]{3}{*}{ Not recorded } & 2 & 1 & 0 & 0 & 1 & 2 & 1 & 1 & 0 & 0 \\
\hline & \multicolumn{2}{|c|}{ All Managers Hearings $(N=172)$} & \multicolumn{2}{|c|}{1 st $(N=80)$} & \multicolumn{2}{|c|}{ 2nd $(N=55)$} & \multicolumn{2}{|c|}{$3 \mathrm{rd}(N=26)$} & \multicolumn{2}{|c|}{4 th-6th $(N=11)$} \\
\hline & $n$ & $\%$ & $n$ & $\%$ & $n$ & $\%$ & $n$ & $\%$ & $n$ & $\%$ \\
\hline \multicolumn{11}{|l|}{ Manager Hearings outcomes } \\
\hline Continued CTO & 163 & 95 & 75 & 94 & 54 & 98 & 25 & 96 & 9 & 82 \\
\hline Discharged to voluntary care & 2 & 1 & 0 & 0 & 1 & 2 & 0 & 0 & 1 & 9 \\
\hline Adjournment & 7 & 4 & 5 & 6 & 0 & 0 & 1 & 4 & 1 & 9 \\
\hline Not recorded & 0 & 0 & 0 & 0 & 0 & 0 & 0 & 0 & 0 & 0 \\
\hline
\end{tabular}

CTO community treatment order, MHRT Mental Health Review Tribunals 
Table 4 Outcomes of hearings by the Mental Health Review Tribunal and hospital managers by time period

\begin{tabular}{|c|c|c|c|c|c|c|c|c|c|c|c|c|}
\hline & \multicolumn{6}{|c|}{$0-12$ th month } & \multicolumn{6}{|c|}{ 13-36 month } \\
\hline & \multicolumn{2}{|c|}{ 1st $(N=53)$} & \multicolumn{2}{|c|}{ 2nd $(N=22)$} & \multicolumn{2}{|c|}{ 3rd-6th $(N=3)$} & \multicolumn{2}{|c|}{1 st $(N=24)$} & \multicolumn{2}{|c|}{ 2nd $(N=20)$} & \multicolumn{2}{|c|}{$3-6$ th $(N=17)$} \\
\hline & $n$ & $\%$ & $n$ & $\%$ & $n$ & $\%$ & $n$ & $\%$ & $n$ & $\%$ & $n$ & $\%$ \\
\hline \multicolumn{13}{|l|}{ Outcome of MHRT Hearings } \\
\hline Continued CTO & 39 & 74 & 16 & 73 & 1 & 33 & 19 & 79 & 15 & 75 & 15 & 88 \\
\hline Discharged to voluntary care & 7 & 13 & 2 & 9 & 0 & 0 & 2 & 8 & 3 & 15 & 0 & 0 \\
\hline Adjournment & 7 & 13 & 3 & 13 & 1 & 33 & 3 & 13 & 2 & 10 & 2 & 12 \\
\hline \multirow[t]{2}{*}{ Not recorded } & 0 & 0 & 1 & 5 & 1 & 33 & 0 & 0 & 0 & 0 & 0 & 0 \\
\hline & \multicolumn{2}{|c|}{$(n=50)$} & \multicolumn{2}{|c|}{$(n=7)$} & \multicolumn{2}{|c|}{$(n=0)$} & \multicolumn{2}{|c|}{$(n=30)$} & \multicolumn{2}{|c|}{$(n=48)$} & \multicolumn{2}{|c|}{$(n=37)$} \\
\hline \multicolumn{13}{|l|}{ Outcomes of Managers Hearings } \\
\hline Continued CTO & 46 & 92 & & 100 & & - & 29 & 97 & 47 & 98 & & 92 \\
\hline Discharged to voluntary care & 0 & 0 & & 0 & & - & 0 & 0 & 1 & 2 & & 3 \\
\hline Adjournment & 4 & 8 & & 0 & & - & 1 & 3 & 0 & 0 & & 5 \\
\hline Not recorded & 0 & 0 & & 0 & & - & 0 & 0 & 0 & 0 & & 0 \\
\hline
\end{tabular}

MHRT Mental Health Review Tribunals, - Not applicable

adjourned. The pattern remained relatively stable for patients' successive hearings by both the MHRT and managers. It was also stable across periods 1 and 2, as shown in Table 4.

\section{Continuous coercion}

Seventy three percent of patients (144/198) had one CTO episode during the 36-month follow-up. Twenty percent (39/198) of patients had two CTO episodes, five percent (10/198) had three, and two percent (4/198) had four. One patient (who was excluded from analyses of conditions) had five CTO episodes.

This means that $27 \%$ of patients $(54 / 198)$ had more than one episode. A third of these $(33 \%, 18 / 54)$ were voluntary patients between CTO episodes: 12 were voluntary outpatients and 6 had a combination of voluntary outpatient and inpatient status between CTO episodes. Among patients with more than one CTO episode, 65\% (35/54) were on continuous coercion from their first CTO until the end of follow-up. This represents $18 \%$ of the total sample of 198 .

\section{Discussion}

Our sample were predominantly male. Most had a diagnosis of schizophrenia, were severely ill, and had long histories of service contact. They closely match samples in UK and international CTO studies [5, 12, 13, 22, 23].

Each CTO had around three discretionary conditions imposed and this number remained fairly constant over time. Medication adherence was a near universal condition, and almost all patients were required to keep appointments and make themselves accessible to services. Conditions of residency accounted for just under a third of all conditions. Other conditions, such as abstaining from drug and alcohol, blood tests, or attending various treatment activities, were applied in 10-20\% of CTOs. Similar patterns are reported in local studies [5-7, 24, 25]. Very specific conditions, such as to check mail regularly or allowing family members to have contact with services, were only occasionally used. The range of conditions narrowed over time: at the end of the study, they were predominantly simple, possible to enforce and concerned medication and service contact. Contact conditions were increasingly specific about how patients were required to engage with their team. This change may reflect learning over time. Our results correspond to findings that psychiatrists believe conditions must be enforceable to be useful, and that medication and contact are those considered most helpful [26].

Overall, a few Managers Hearings (1\%, 2/172) or MHRT Hearings $(10 \%, 14 / 139)$ resulted in discharge from CTO. The latter is slightly higher than the 5\% reported in national figures [8]. Despite the difference in discharge levels between Managers Hearings and MHRT Hearings, our observed discharge level is still low, suggesting that clinical decision-making is in line with how the law is interpreted by administrators and mental health judges.

We have reported earlier that the 198 patients remained on CTO for a median of 346 days (IQR 180-724) over the 36 months [16]. We now know that $18 \%$ of them remained under compulsion until the end of the observation, so this reported median may be an underestimate. CTO patients experience prolonged periods under 
compulsion, and for a subgroup of patients, these are particularly lengthy.

\section{Strength and weaknesses}

This descriptive analysis is the first to investigate CTO use in England over a prolonged period of 36 months. A key strength is the degree of data completeness for a group of severely ill patients [16] and possible generalisability as they were recruited from 32 different NHS hospitals, covering urban, suburban, and rural populations [14]. Caution is required when interpreting percentages from small samples.

\section{Conclusions}

CTOs in England seem to be used to oblige patients to take their medication and to stay in contact with services. A third is also obliged to reside at a specified address. There is agreement between clinical and legal judgements about the threshold for remaining on a CTO. The pattern of continuous coercion for a significant group of patients adds to concerns about the 'lobster pot' effect. The current increase in CTO prevalence [8] despite the evidence of no patient benefit [11-13] should give cause for concern, and especially so in light of the overall increase in the use of the MHA [8]. Implementation should be carefully monitored in further cohort studies with adequate long-term follow-up.

Acknowledgements This article presents independent research funded by the National Institute of Health Research (Program Grant for Applied Research, Grant No. RP-PG-0606-1006). The views expressed in this publication are those of the authors and not necessarily those of the NHS, the NIHR or the Department of Health. We are grateful to the OCTET researchers: Caroline Bennett, Kiki Burns, Krysia Canvin, Alexandra Forrest, Lindsey Johnston, Naomi Lewis, Sarah Masson, Andrew Molodynski, Lucy Murray, Helen Nightingale, Riti Patel, Stephen Puntis, Lisa Russell, Aonghus Ryan, Tanya Smith, Anna Sulman, Lucinda Turnpenny, Amy Mitchell, Maria Vazquez Montes, Francis Vergunst, Claire Visser, and Sue WoodsGanz.

\section{Compliance with ethical standards}

\section{Conflict of interest None.}

\section{References}

1. Rugkåsa J, Molodynski A, Burns T (2016) Introduction. In: Molodynski A, Rugkåsa J, Burns T (eds) Coercion in Community Mental Health Care. International Perspectives. Oxford University Press, Oxford, pp 1-9

2. Rugkåsa J, Burns T (2009) Community treatment orders. Psychiatry $8(12): 493-495$
3. Department of Health (2008a) Mental Health Act 2007: Patients on after care under supervision (ACUS) Transitional arrangements

4. Swartz M, Swanson JW, Steadman HJ, Robbins PC, Monahan J (2009) New York State Assisted Outpatient Treatment Program Evaluation. Duke University School of Medicine, Durham

5. Smith M, Branton T, Cardno A (2014) Is the bark worse than the bite? Additional conditions used within community treatment orders. Psychiatr Bull 38(1):9-12. doi:10.1192/pb.bp.113.043422

6. Lepping P, Malik M (2013) Community treatment orders: current practice and a framework to aid clinicians. Psychiatr 37(2):54-57. doi:10.1192/pb.bp.111.037705

7. Monnery D, Belgamwar RB (2011) Use of supervised community treatment in one UK healthcare district. Prog Neurol Psychiatry $15(6): 8-13$

8. HSCIC (2016) Inpatients Formally Detained in Hospitals Under the Mental Health Act 1983 and Patients Subject to Supervised Community Treatment, England: 2014-2015, Annual figures. Health and Social Care Information Centre. Accessed 27.06.2016 2016

9. Kisely S, Hall K (2014) An updated meta-analysis of randomized controlled evidence for the effectiveness of community treatment order. Can J Psychiatry 59(10):561-564

10. Kisely S, Campbell LA, Scott A, Preston NJ, Xiao J (2007) Randomized and non-randomized evidence for the effect of compulsory community and involuntary out-patient treatment on health service use: systematic review and meta-analysis. Psychol Med 37(1):3-14. doi:10.1017/S0033291706008592

11. Maughan D, Molodynski A, Rugkåsa J, Burns T (2014) A systematic review of the effect of community treatment orders on service use. Soc Psychiatry Psychiatr Epidemiol 49(4):651-663. doi:10.1007/s00127-013-0781-0

12. Churchill R, Owen G, Singh S, Hotopf M (2007) International experiences of using community treatment orders. Institute of Psychiatry, London

13. Rugkåsa $\mathbf{J}$ (2016) Effectiveness of community treatment orders: the international evidence. Can J Pscyhiatry 61(1):15-24

14. Burns T, Rugkåsa J, Molodynski A, Dawson J, Yeeles K, Vazquez-Montes M, Voysey M, Sinclair J, Priebe S (2013) Community treatment orders for patients with psychosis (OCTET): a randomised controlled trial. Lancet 381(9878):1627-1633. doi:10.1016/S0140-6736\%2813\%2960107-5

15. Rugkåsa J, Vazquez Montes M, Bennett C, Burns K, Burns T, Canvin K, Dawson J, Dunn M, Gray A, Johnston L, Lewis N, Masson S, Molodynski A, Murray L, Nightingale H, Patel R, Priebe S, Puntis S, Russell L, Ryan A, Simon J, Sinclair J, Smith T, Sulman A, Turnpenny L, Mitchell A, Montes MV, Vergunst F, Visser C, Wood-Ganz S, Voysey M, Yeeles K (2015) Community treatment orders: clinical and social outcomes, and a subgroup analysis from the OCTET RCT. Acta Psychiatr Scand 131(5):321-329. doi:10.1111/acps.12373

16. Burns T, Yeeles K, Koshiaris C, Vazquez-Montes M, Molodynski A, Puntis S, Vergunst F, Forrest A, Mitchell A, Burns K, Rugkåsa J (2015) Effect of increased compulsion on readmission to hospital or disengagement from community services for patients with psychosis: follow-up of a cohort from the OCTET trial. Lancet Psychiatry. doi:10.1016/s2215-0366(15)00231-x

17. Rugkåsa J, Yeeles K, Koshiaris C, Burns T (in press) Recall of patients on community treatment orders. A three-year follow-up of the OCTET CTO cohort. BMC Psychiatry

18. Curtis D (2014) OCTET does not demonstrate a lack of effectiveness for community treatment orders. Psychiatr Bull 38(1):36-39. doi:10.1192/pb.bp.113.044800

19. Mustafa FA (2014) On the OCTET and supervised community treatment orders. Med Sci Law 54(2):116-117. doi:10.1177/ 0025802413506898 
20. Goldman HH, Skodol AE, Lave TR (1992) Revising axis V for DSM-IV: a review of measures of social functioning. Am $\mathbf{J}$ Psychiatry 149(9):1148-1156

21. Lukoff D, Nuechterlein K, Ventura J (1986) Manual for expanded brief psychiatric rating scale (BPRS). Schizophr Bull 12(4):594-602

22. Evans R, Makala J, Humphreys M, Mohan CRN (2010) Supervised community treatment in Birmingham and Solihull: first 6 months. Psychiatr 34(8):330-333. doi:10.1192/pb.bp.109.027482

23. Rawala M, Gupta S (2014) Use of community treatment orders in an inner-London assertive outreach service. Psychiatr Bull 38(1):13-18. doi:10.1192/pb.bp.112.042184
24. Dye S, Dannaram S, Loynes B, Dickenson R (2012) Supervised community treatment: 2-year follow-up study in Suffolk. Psychiatr Bull 36:298-302. doi:10.1192/pb.bp.111.036657

25. Malik M, Hussein N (2009) Qualitative outcome for community treatment orders. Psychiatr 33(11):437-438. doi:10.1192/pb.33. $11.437 \mathrm{a}$

26. Canvin K, Rugkåsa J, Sinclair J, Burns T (2014) Patient, psychiatrist and family carer experiences of community treatment orders: qualitative study. Soc Psychiatry Psychiatr Epidemiol 49(12):1873-1882. doi:10.1007/s00127-014-0906-0 